\title{
Fuzzy Cognitive Network by Adaptive Fuzzy PID Controller and Hybrid Optimization Algorithm
}

\author{
Amit Chouksey*, S. Awasthi and S. K. Singh
}

Electronics and Communication, Jayoti Vidyapeeth Women's University, Jaipur-303122, Rajasthan, India; amitchoukseyzee@gmail.com, awasthiszee@gmail.com, sankumarsinghzee@gmail.com

\begin{abstract}
Objectives: To improve the power produced by a photovoltaic system under varying climatic circumstances and thus improving the convergence speed. Methods: To improve power in this work a Fuzzy PID regulator is implemented which is tuned by hybrid Artificial Neural Network - Particle Swarm Optimization - Simulated Annealing (ANN-PSO-SA) and FCN (Fuzzy Cognitive Network) optimization algorithm. Additionally a DC/DC help converter is employed to regulate the yield intensity of the photovoltaic system. Findings: The proposed technique works on maximum power point and improves the performances of solar energy conversion capability and maintains system stability in case of quickly unstable atmospheric rules. To the best of knowledge no PID controller or regulator has implemented this hybrid optimization algorithm along with fuzzy concepts and works with differing climatic conditions. This method achieves the advantages of the fuzzy techniques along with optimization techniques. Along with achieving maximum power the proposed controller achieves constant voltage control. The DC-DC boost converter makes use of the output of PV panel and is responsible for regulating the output power. The FCN utilized is responsible for maintaining an equilibrium condition at varying climatic conditions. Improvements: The tuned controller is compared to the conventional MPPT algorithms with specification rise time, overshoot and delay time. This is demonstrated in the comparison results shown in the results section.
\end{abstract}

Keywords: DC/DC Help Converter, Fuzzy Cognitive Network (FCN), Maximum Power Point Tracking (MPPT) and Photovoltaic (PV) System

\section{Introduction}

With the continuous fall in the price of photovoltaic (PV) sector and the rising involvement on the ozone depleting substance emanations, solar energy is quickly becoming an important power source in the worldwide energy scenario ${ }^{1}$. PV system is moderately simple to introduce, safe, nearly maintenance free and all the more importantly, condition cordial. Extensive PV control systems are being introduced worldwide because of their medium and long haul economic prospects 2 . Also, it needs low preservation, no clamor and wears due to the lack of giving parts which makes solar power attractive ${ }^{3}$. Each kind of PV modules own specifies elements corresponds to the encompassing rules such as light, and temperature and it make the tracking of most extreme power point (MPP) a complicated issue ${ }^{4}$. Most MPPT control algorithm is required to modify continuously the power interfaces to get the greatest power accessible from a PV exhibit at some random time under factor conditions (disconnection, shading, temperature and burden) ${ }^{5}$.

There is a one of a kind working on the cluster's capacity - voltage (P-V) curve called the MPP where generation of power is utmost ${ }^{6}$. A MPPT controller detects the current and voltage of the PV cluster; the power is measured and accordingly the obligation cycle of the converted is acclimated to match the $\mathrm{MPP}^{\mathrm{z}}$. Numerous most extreme power points tracking (MPPT) control algorithms have been introduced already ${ }^{-}$. MPPT fuzzy logic controllers (FLC) are generally easy to model 
as they don't require the learning of the exact exemplary? They also have the advantage of being quick robust and great performance (time reaction, solidness, tracking speed, little oscillations) under differing atmospheric conditions. These controllers are progressively effective under unexpected changes of atmospheric conditions comparing to the customary algorithms $\mathrm{s}^{10}$.

Inspired of the fact that, there are numerous factors influencing energy conversion efficiency, the MPPT is the main essential feature of control design in a PV structure ${ }^{11}$. The unreliable changes of the ecological rule influence the PV characteristics and parameters appreciably ${ }^{12}$. Ideal tuning of DC-DC converters is important due to their impact on sustainable power source systems $s^{\underline{13}}$. Intelligent optimization methods are many successful methods in tuning of DC-DC converters ${ }^{14}$. A fuzzy-PID control utilizing fuzzy rules based algorithm is proposed. Other than completing the MPPT control, this also completes the constant voltage output control $1 \frac{15}{}$. These controllers are increasingly effective under abrupt changes of atmospheric conditions shared to the conventional algorithms $s^{16}$. In any case, the dependability relies upon the information of the control engineer who decides the fuzzy standard base and chooses the fuzzy parameters are mistake metrics, enrollment functions and scaling factors with accuracy ${ }^{17}$. Also the PID controller tuned by Cuckoo Search Optimization (CSO) is given in $\frac{18}{}$.

Inspired of the fact that few algorithms have being proposed already some different issues are identified with the PV system such as the power fluctuation because of temperature changes, overvoltage along the circulation feeder because of switch control stream, voltage fluctuations at purpose of typical coupling (PCC), because of irregular power generation of the PV systems, frequency varieties in little power systems, low power component of auctioning conveyance transformer.

The proposed work addresses about few of the above issues. The proposed technique involves Fuzzy PID (proportional-integral-derivative) controller tuned by hybrid ann- pso-SA followed by FCN. The paper content is given as follows. Section 2 discussed few recent related existing researches. Section 3 portrayed the proposed methodology in PV system. Section 4analyzes the work results by providing comparison with some existing approaches. Finally, conclusions are contributed in Section 5 followed by the references. Several researchers have implemented diverse techniques to tribute the energy of the solar cell by augmenting the MPPT techniques through previous decades. A portion of the recent works is recorded beneath:

In ${ }^{19}$ designed a MPPT controller for PV systems employing a Fuzzy Gain Scheduling of PID type controller (FGS-PID) with adjustment of scaling component (SF) for the info signals of FGS. The proposed versatile FGS-PID technique depended on a two-level control system architecture, which combined the fuzzy logic and conventional PID control advantages. The underlying estimations of the PID's additions were controlled by the Zieglere Nichols tuning technique. During transient and consistent states, the PID's additions were adjusted by the FGS-PID to soggy out the transient oscillations, to reduce settling time and to guarantee system soundness and accuracy. Also, the conditioned information signals of the FGS-PID were tuned dynamically by addition factors which depended on fuzzy logic system (FLS). The FLS was characterized by a lot of fuzzy principles which are fuzzy conditional articulations communicating the connection between information sources (blunder and change of mistake) and yields.

$\mathrm{In}^{20}$ described the occurrence of serious flaws, by which the power system transient strength might be endangered. Then the quick active power control capacity of the PV inverter lead to the likelihood of transient dependability improvement. This paper focused on the fuzzy addition scheduling of PID (FGS-PID) controller for transient adjustment of a multi-machine control system. The FGS-PID controller was utilized to controlling the PV inverter; with the objective that the PV control gives in can be regulated to balance out the transient power swing when the flaws happen. To acquire the balancing out performance, the scale factors, enrollment functions, and control guidelines of the FGS-PID controller were dictated by a honey bee colony optimization. Furthermore beyond unsuccessful the fundamental function of intensity generation, the PV with FGS-PID control supply energy to the system practically equivalent as the PV with MPPT, during adjustment.

$\mathrm{In}^{21}$ exhibited an investigation of the advancement of a dynamic model dependent on hypotheses of PID control and optimization to assess the coordinated performance of the energy generation and storage system. The half breed system consists of photovoltaic (PV) generator, water generator $(\mathrm{GH})$ and power device (FC), connected to a DC (direct current) bus. A converter (DC/AC) was utilized between the bus and the heap to change the energy 
into acceptable levels of consumption. Least conditions of interruption and voltage level within the specified range were vital setting for electric energy supply. To overcome the inadequacies of the architecture and the low light incident on the modules and reduction of the hydraulic stream, a closed circle controller was associated to the energy component; assuring the performance of the gathering.

$\mathrm{In}^{22}$ showed the ideal design measures to tune controller parameters for network connected shared generation system reliant on cuckoo search algorithm (CSA). To examine the performance of implemented algorithm, a matrix tied PV system comprising of two power electronic converters enclosed by five corresponding vital PI controllers was elected. Setting genuine qualities for all the PI controllers was a complex task, strikingly when the system was non-linear. Reaction Surface Methodology (RSM) was used to construct up the mathematical design of the PV system which was mandatory to relate the optimization algorithm. To bind the design endeavors of RSM, a substitute approach needy on ANN was introduced to build up the mathematical model of the PV system. In addition, two modifications in the CSA were implemented to extracting ideal parameters for the controllers.

$\mathrm{In}^{23}$ described the judgment conditions and variable advance size functions in the auto-scaling variables advance size (ASVSS) MPPT strategy possess the characteristic of auto-convergence. This work connected the above procedures as the info factors of the fuzzylogic theoretical system and during the handing out of fuzzification, inference, and defuzzification, the MPPT system can achieve the benefits of good transient tracking capability and better consistent state property. The uses of auto-scaling factors of ASVSS strategy and fuzzylogic control were coordinated then the achievement of the solar system can be additionally improved. The lift converter was utilized as the MPPT topology and the advanced signal processor TMS 320LF2407 was utilized to control the fuzzy computerized process and yield the PWM signal to the driving switch to modify the heap impedance to match that of the solar cluster to understand the MPPT.

$\mathrm{In}^{24}$ presented the frequency control design for a half and half segregated power system with sort 2 fuzzy logic PID controller. The proposed system consisted of two topologies with different generation sources. The first topology consisted of a wind turbine generator (WTG) with a diesel engine generator (DEG). The next topology consists of a (PV) and micro-hydropower system (MHP) with a DEG. This paper proposed a control approach for using a polymer electrolyte film power device (PEMFC) as an energy storage system to keep away from frequency deviation. Electrolyzer of PEMFC assimilates a piece of the created energy from WTG/PV- MHP to produce fuel (hydrogen) for the power device requirement. The main contribution in this work is as follows:

- A fuzzy PID controller is utilized to maintain maximum power in PV system under various climatic circumstances (temperature and irradiance).

- Then a hybrid ANN-PSO-SA optimization technique is given to tune the output power of Fuzzy PID controller pursued by DC/DC boost converter that make the most of the output voltage to maximize PV power generation.

- Finally FCN is also implemented in PV system which is responsible to maintain the equilibrium state of $\mathrm{PV}$ system.

\section{Proposed Methodology}

PV cell is an electrical device that was converted by the energy of light directly into electricity by the photovoltaic effect. PV modules are ended of an assembly of PV cells which are connected together in arrangement as well as parallel circuits to producing higher voltages, currents, and power levels. The acquired energy relies upon solar illumination, the temperature, the spectral distinctiveness of daylight, shaded condition, the soil, and capitulate voltage of the PV modules, etc. The power obtained from PV system varies due to various climatic rules, while working with the power fluctuation voltage issues are also identified over-voltages along the shared feeder due to reversing power flow.

To overcome the aforementioned issues in the proposed work a robust Fuzzy PID controller employed with ANN- hybrid SA-PSO to track the MPP with high tracking speed and maintain the system stability by tuning the parameters of PV system i.e. power. This algorithm can is recycled to build a fuzzy link and make a rough prediction. This power circuit also consist of high output voltage DC-DC boost converter which make best use of the output of PV panel thus regulating the output power. Consequently a FCN algorithm is given to perform intense 
decision making of the power system and online control with minimum set-up time. Then the equilibrium state will be maintained that improve the conversion efficiency. The overall architecture of the proposed methodology is depicted in Figure 1 architecture diagram.

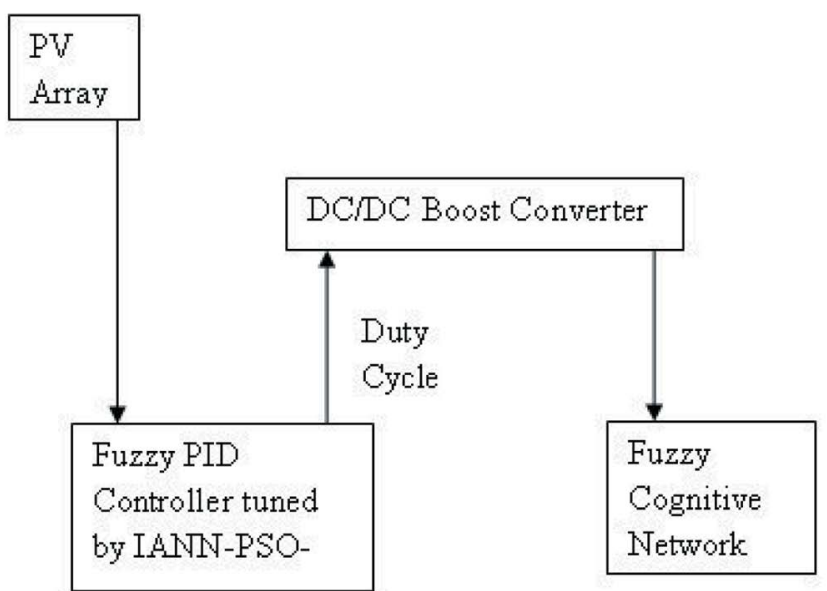

Figure 1. Architecture of proposed methodology.

The PV generator is shaped by the combination of numerous PV cells connecting in arrangement and parallel design to give wanted estimation of yield voltage and current. Solar cell consists of one diode parallel with a photograph current source. To have increasingly accurate model arrangement resistance and parallel resistance is added to this combination. is the yield current of $\mathrm{PV}$ exhibit, is the cell photocurrent that is corresponding to solar enlightenment, is the current throughout the diode, and are the array and evade resistors of the cell. The output current of the solar cell is articulated as in (1)

$I_{o}=N_{p} I_{p h}-N_{p} I_{r s}\left[e^{\left(\frac{q\left(v+R_{s} J_{o}\right)}{A \cdot k \cdot T \cdot N_{S}}\right)}-1\right]-N_{p}\left(\left(q\left(v+R_{S} I_{0}\right)\right) /\left(N_{s} \cdot R_{s h}\right)\right)$

Where $I_{r s}$ is the cell reverse saturation current, $V$ is the cell output voltage, $N_{s}$ is the PV cells count associated in lines, $N_{p}$ is the PV cells count in parallel, $A$ is the diode ideality constant, $k$ is the Boltzmann's constant and is equal to $1.3806503 \times 10-23 \mathrm{~J} / \mathrm{K}, q$ is the electron charge and is $1.60217646 \times 10-19 \mathrm{C}, \mathrm{T}$ is the temperature calculated in Kelvin.

The generated photocurrent $I_{p h}$ is linked to the solar irradiation as in (2)

$$
I_{p h}=\left[I_{\varepsilon}+k_{i}\left(\left(T-T_{r}\right)\right](S / 1000)\right.
$$

Where is $I_{s c}$ the cell short-circuit current temperature, $k_{i}$ is the short-circuit current temperature coefficient, $T_{r}$ is the cell reference temperature, $S$ is the solar irradiation specified in $\mathrm{W} / \mathrm{m} 2$. The cell's saturation current $I_{r s}$ varies with temperature as in (3)

$$
I_{s}=I_{r}\left[T / T_{r}\right]^{3} \exp \left(\left(q \cdot E_{G}\right) /(k \cdot A)\left[(1) /\left(T_{r}\right)-(1 / T)\right]\right)
$$

Where $I_{r r}$ is the inverted saturation at $T_{r}$ (cell reference temperature), $E_{G}$ is the band-gap energy of the semiconductor.

\subsection{Fuzzy Pid Controller}

The parameters from PV system are fed as input to the Fuzzy PID controller. A fuzzy logic system is added in order to determine online the parameters of the PID. The integral time constant is resolute with suggestion to the secondary time stable. The transfer function of PID controller is specified as in (4)

$$
\operatorname{TransFn}_{P I D}=K_{p}+\frac{K_{I}}{s}+K_{D} \cdot s
$$

Where $K_{p}, K_{I}$ and $K_{D}$ are the proportional, integral and derivative gain of the controller. Fuzzy PID controller integrates fuzzy proportion integral (PI) and fuzzy proportional-derivative (PD) controllers. The input scaling factors are $K_{1}$ and $K_{2}$ and the output scaling factors are $K_{3}$ and $K_{4}$. The membership function for input and output are taken as -10 to 10 and -1 to 1 respectively. Controller parameters are optimized with the benefit of hybrid IANN-PSO-SA Optimization. Integral squared error (ISE) is used as objective function for controller parameters optimization.

$$
\text { objfun }=I S E=\int_{0}^{t_{\text {sim }}}\left(\Delta F_{i}^{2}+\Delta P_{t i e-i, j}^{2}\right) d
$$

Where $\Delta F_{i}$ is the system frequency deviation of I th -area; $\Delta P_{t i e-i j}$ is the incremental change in tie line power. $t_{\text {sim }}$ is the time range of simulation. Consequently, the optimization problem is stated as in (6)

Minimize objfun 


$$
\left.\begin{array}{l}
\left.\begin{array}{l}
K_{P}^{\min } \leq K_{p} \leq K_{P}^{\max } \\
K_{I}^{\min } \leq K_{I} \leq K_{I}^{\max } \\
K_{D}^{\min } \leq K_{D} \leq K_{D}^{\max }
\end{array}\right\} \text { for PID controller } \\
K_{1}^{\min } \leq K_{1} \leq K_{1}^{\max } \\
K_{2}^{\min } \leq K_{2} \leq K_{2}^{\max } \\
K_{3}^{\min } \leq K_{3} \leq K_{3}^{\max } \\
K_{4}^{\min } \leq K_{4} \leq K_{4}^{\max }
\end{array}\right\} \text { for Fuzzy PID control }
$$

Further than the classical PID controller with a smaller amount effectiveness the proposed fuzzy PID controller achieves maximum output power and also withstands under varying environmental conditions (temperature and irradiance).

\subsection{Hybrid ANN-PSO-SA Optimization}

The output from fuzzy PID controller is given to hybrid ANN- PSO-SA for further tuning the output parameters. The implemented hybrid ANN- PSO-SA combines the functions of $\mathrm{ANN}$ and PSO-SA to improve the performance of PV systems under varied weather conditions. Generally the ANN is trained using prior dataset that comprises of various levels of irradiances, temperatures, open circuit voltages $\left(V_{o c}\right)$, short circuit currents $\left(I_{s c}\right), \mathrm{PV}$ currents $\left(I_{p v}\right)$ and $\mathrm{PV}$ voltages $\left(V_{p v}\right)$ for training and to predict the output for a particular weather condition while the PSO-SA algorithm plays the vital role for optimization. This PSO-SA is used for prediction in this implemented hybrid algorithm ${ }^{25}$. In PSO, the position of particles in the trouble space is defined as the result of optimal crisis, and the fitness value that guesses the value of particles is the result of objective formulation. Consequently the process of SA is similar with the process of solid annealing. According to characteristics of the SA and PSO algorithm, this work gives a joint algorithm based on PSO and $\mathrm{SA}^{26}$ for $\mathrm{PV}$ system optimization. In the calculation process, PSO and SA alternate to calculate, and compare the objective function value with each other to calculate approximately the value of result. If the solution of $\mathrm{SA}$ is better, then replace a random particle with it to add the variety of the particles. If the solution of PSO is better, then take it as the initial solution of SA in the next iteration in the lower temperature to enhance the searching efficiency of SA. The calculation step of PSO and SA (PSO- SA) is described by the following steps.

1) Initialize particles, calculate objective functions to determine $p_{i}$ and $p_{g}$ of each particle; set the initial solution $x_{0}$ of SA as $p_{g}$ and objective function value $y_{0}$ as $f\left(p_{g}\right)$;

2) Perform a SA search. Beginning with the initial solution $x_{0}$ at the temperature $\mathrm{T}$, create new solution and estimate it with Metropolis Rules continually until iterative time, and receive a new solution $x^{\prime}$. Reduce the temperature by $T=K^{*} T$;

3) Perform PSO search. Calculate objective function for $m$ times by the position of all particles and revise the particle's velocity and position and $p_{g}$, add to the iterative time.

4) Compare the objective function value that is determined by $x^{\prime}$ and $p_{g}$, if $f(x)<f\left(p_{g}\right)$, chose a random particle and set its position $x_{i}=x^{\prime}$, return 3; if $f\left(x^{\prime}\right)>f\left(p_{g}\right)$, set $x_{0}=p_{g}$ and return 2 ; if $f\left(x^{\prime}\right)=f\left(p_{g}\right)$ and the ending conditions are satisfied, end the calculation, otherwise return 2 . These steps are described pictorially in Figure 2 proposed optimization flowchart.

\subsection{DC- DC Boost Converter}

The DC/DC boost converter boosts the yield voltage from the optimization algorithm. To guarantee the operation point on the greatest power point specific circuit MPPT is utilized. The MPPT is achieved by mediating DC-DC help converter between the PV generator and the heap (battery), in this way, acting on the converter obligation cycle (D) to guarantee the operation point. The earnings of the converter is hugely inclined by the switching frequency i.e. gate pulse. The output of the converter is specified as in (9)

$$
V_{\text {out }}=\frac{1}{1-D} V_{\text {in }}
$$

The duty cycle $\mathrm{D}$ of the converter is as in (10)

$$
D=\frac{t_{o n}}{t_{o n}+t_{\text {off }}}
$$




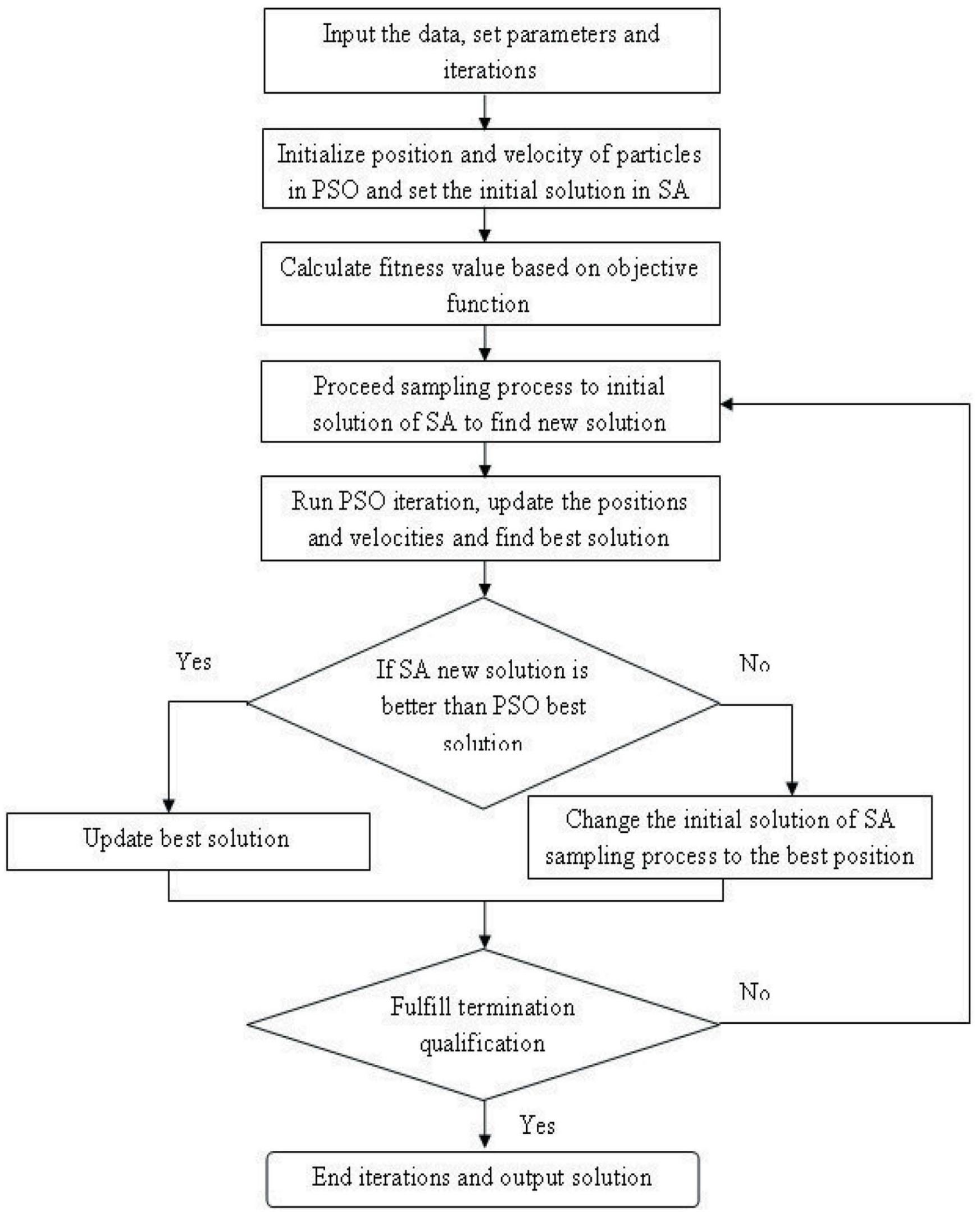

Figure 2. Flowchart describing PSO-SA optimization. 
On time and off time of the switch are articulated in (11) and (12) by giving way switching period $\left(T_{s}\right)$.

$$
\begin{aligned}
& t_{\text {on }}=D T_{s} \\
& t_{\text {off }}=(1-D) T_{s}
\end{aligned}
$$

Thus the output voltage attained is boosted by duty cycle in DC/DC boost converter.

\subsection{Fuzzy Cognitive Network}

Fuzzy cognitive maps ${ }^{27}$ approach is a half breed modeling procedure, neglecting individuality of both fuzzy logic and neural networks hypotheses and assumes an important job in the advancement of PV systems. The intensity of cognitive maps is enhanced by considering fuzzy qualities for their nodes and fuzzy degrees of interrelationships among nodes. FCM is a marked directed chart with feedback subsists of nodes and weighted interconnections. Nodes describe the conduct of the system and they are connected by marked and weighted arcs speaking to the causal connections that exist among nodes. Each node speaks to a characteristic of the system. By and large it represents states, factors, moment, actions, objectives, values, patterns of the system which is modeled as a FCM.

Each node is characterized by a number speaking to its esteem and it results from the change of the genuine estimation of the system's variable, for which this node remains $[0,1]$. The most fundamental part in modeling a system utilizing FCMs is simply the improvement of the fuzzy cognitive guide itself, the guarantee of the nodes that preeminent describe the system, the direction and the explanation of causality amid nodes. The selection of the different factors of the system, which is exhibited in the guide, is the result of a close-up on system's operation conduct as been acquired by specialists. Beyond these lines the harmony of the PV system is also kept up.

\section{Results and Discussions}

The proposed Fuzzy PID controller with hybrid ANNPSO-SA algorithm supported by FCN is proposed in matlab (R2013a). Initial the dataset values from solar array are given as input which is processed by the Fuzzy PID controller. The dataset utilized are bright light datasets and dim light datasets of the PV array. This output is tuned with aid of hybrid ANN-PSO-SA optimization algorithm. Consequently a DC-DC boost converter is set to manage the duty cycle. This is followed by FCN to maintain the equilibrium state of PV system. The hybrid PSO-SA algorithm parameters utilized to initialize the PV system produced an initial random population of individuals symbolize the Fuzzy PID controller gains are defined in Table 1. PSO - SA parameters. Accordingly, the optimum fuzzy PID controller gains are given in Table 2. Fuzzy PID parameters.

Table 1. Pso-sa parameters

\begin{tabular}{|c|c|}
\hline Description & Parameters \\
\hline Population size & 64 \\
\hline Maximum iteration & 50 \\
\hline
\end{tabular}

Table 2. Fuzzy PID parameters

\begin{tabular}{|c|c|}
\hline Gain & Value \\
\hline$K_{p}$ & -6 to 6 \\
\hline$K_{i}$ & -0.6 to 0.6 \\
\hline$K_{d}$ & -6 to 6 \\
\hline
\end{tabular}

The Power value of PV system initially varies from $27.5843 \mathrm{~W}$ to $-2.9145 \mathrm{~W}$. After processing during fuzzy PID controller and by optimization techniques the power value is maximized to $206.6765 \mathrm{~W}$. the output power from PV system is represented in Figure 3 PV system power.

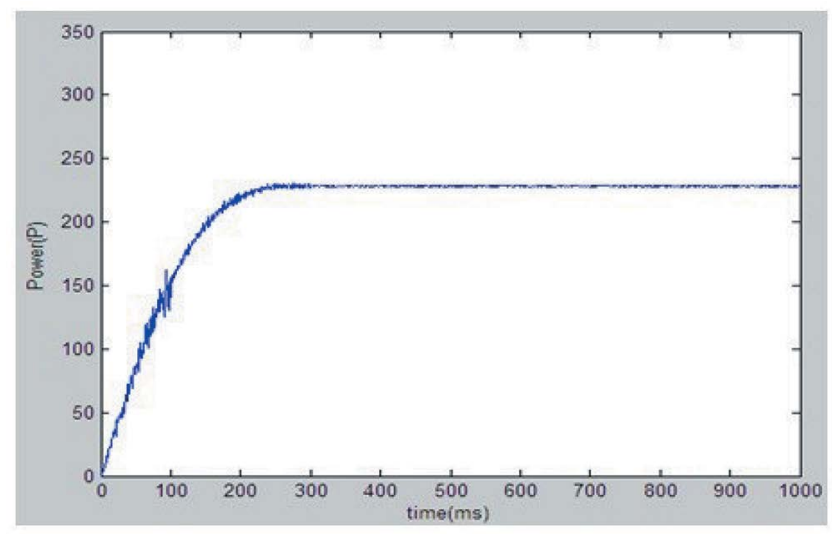

Figure 3. Power in PV system.

Other values of different parameters identified in PV system are tabulated in Table 3. PV system parameters.

Consequently the parameters of the DC/DC boost converter $V_{\max }$ and is equal to 36.6. Here the input voltage values are analyzed between 26.03 to 31.6521 and the 
Table 3. PV System parameters

\begin{tabular}{|c|c|}
\hline Parameters & Value \\
\hline$I_{d}$ & 0.05 \\
\hline$R_{s}$ & 0.393 \\
\hline$R_{s h}$ & 313.4 \\
\hline$N_{s}$ & 60 \\
\hline$A$ & 0.981 \\
\hline
\end{tabular}

output voltage values are examined from 32.2840 to 31.6524. This proves that the DC/DC boost converter maximizes the output voltage and is demonstrated in Figure 4 PV system voltage.

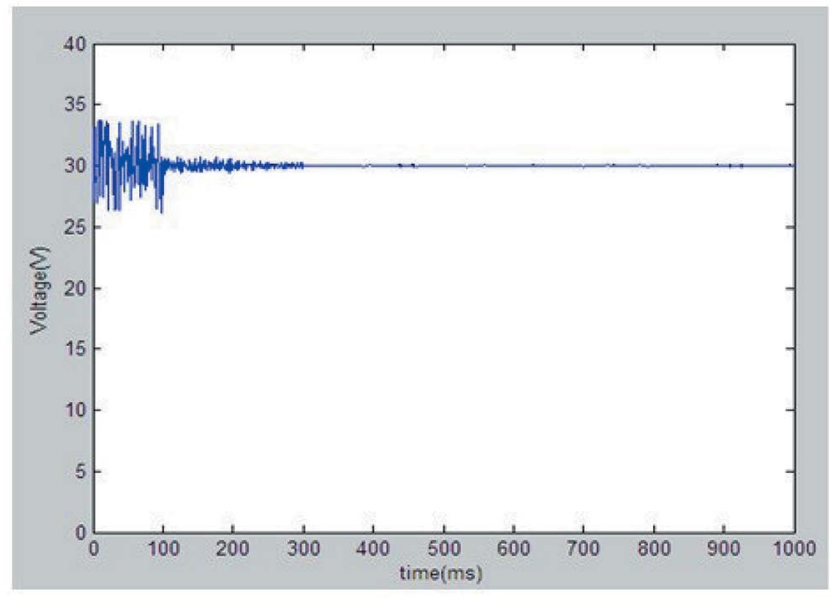

Figure 4. Voltage in PV sytem.

The mathematical expression that describes the I-V characteristics of a PV cell is given in (13)

$$
I=I_{p v, \text { cell }}-I_{0, \text { cell }}\left\{e^{\frac{q V}{\alpha k T}}-1\right\}
$$

Where $I_{p v^{\prime} \text { cell }}$ Is current due to incidence of light, $I_{d}$ is diode current, $I_{0^{\prime} \text { cell }}$ is diode reverse saturation current. PV arrays consist of several series or parallel connected individual PV cells. The I-V characteristics of PV cells are clarified pictorially in Figure $5 \mathrm{~V}$-I characteristic. Also the P-V characteristics of PV cells are represented in Figure 6 $\mathrm{P}-\mathrm{V}$ characteristic.

Table 4 comparison table illustrates the comparison results of the implemented methodology with existing research works. The numerical value in this table illustrates superior performance of the implementing method. The implemented Fuzzy PID controller with the hybrid IANN- PSO-SA improves the tracking efficiency.

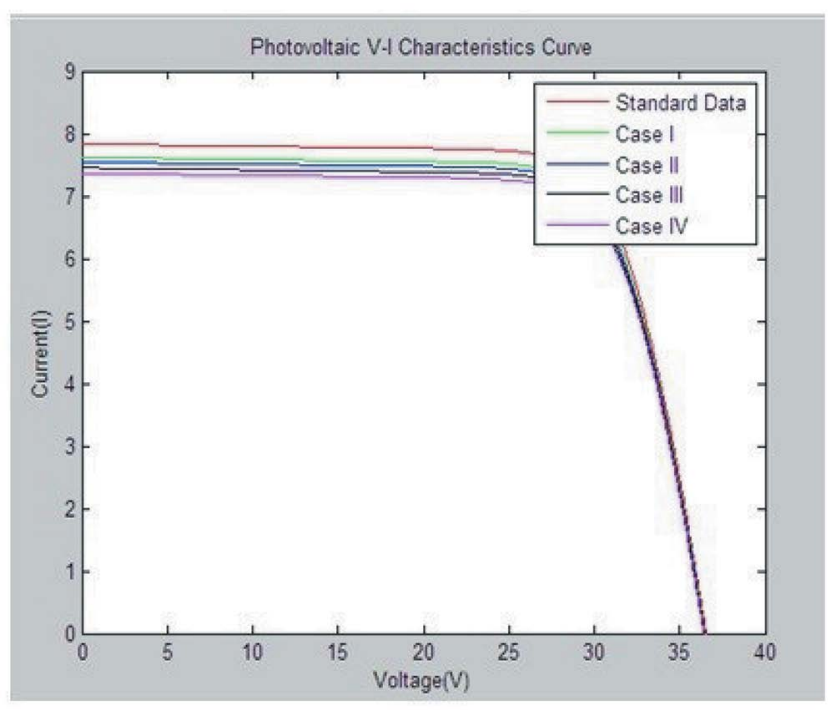

Figure 5. V-I characteristics of the proposed Photovoltaic System.

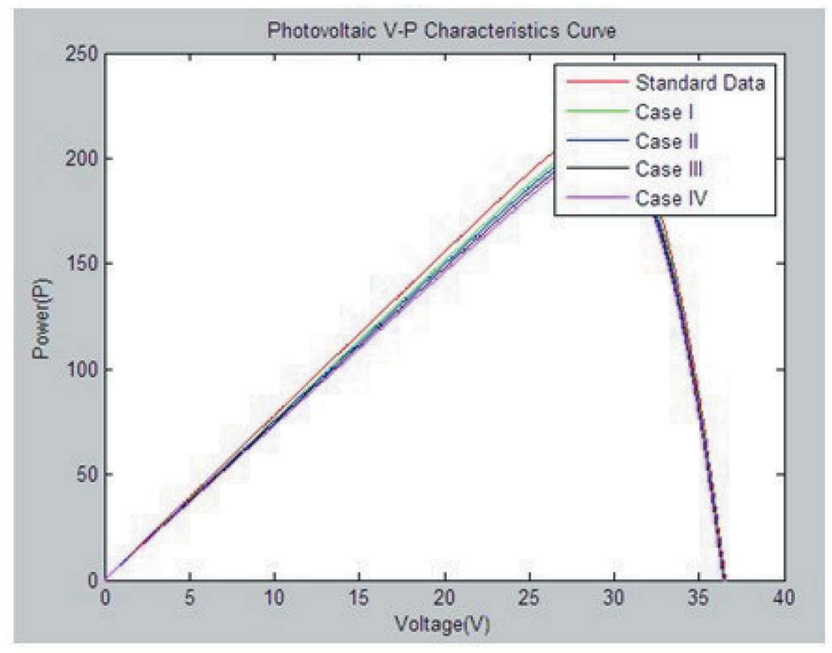

Figure 6. P-V characteristics of the proposed Photovoltaic System.

The comparisons results are provided with the parameters are rise time, overshoot and delay time. The overshoot because of illumination changing is less important in case of proposed algorithm (48.2517) than in case of conventional algorithms such as Intelligent Gene Collector - Particle Swarm Optimization (IGC-PSO), PSO and Fuzzy PID-PSO algorithms. This enhancement of the proposed algorithm is considered maximum, knowing that the duration of rise time measured in milliseconds (17.6067 ms), delay time measured in milliseconds (1 ms) is fewer in the case of proposed algorithm when compared to the existing algorithms. Additionally, settled time and overshoot determine the energy loss in PV system the 
proposed system has only smaller energy losses. Since higher the overshoot and clear time, larger is the energy loss and vice versa.

Table 4. Comparison table

\begin{tabular}{|c|c|c|c|c|}
\hline $\begin{array}{c}\text { Performance } \\
\text { Parameters }\end{array}$ & $\begin{array}{c}\text { IGC- } \\
\text { PSO }\end{array}$ & PSO & $\begin{array}{c}\text { Fuzzy } \\
\text { PID- } \\
\text { PSO }\end{array}$ & $\begin{array}{c}\text { Proposed } \\
\text { Algorithm }\end{array}$ \\
\hline Rise Time & 191.8842 & 205.1216 & 19.1975 & 17.6067 \\
\hline Overshoot & 143.3599 & 60.0061 & 68.7728 & 48.2517 \\
\hline Delay time & -44 & -22 & 1 & 1 \\
\hline
\end{tabular}

\section{Conclusion}

The idea of this work is to design a PV system and to develop the efficiency of the system by accomplishing Fuzzy PID based MPPT technique. In this work the mixture ANN-PSO-SA is utilized to tune the yield from fuzzy PID controller. Additionally to maintain the equilibrium state FCN is utilized. The power and the voltage parameters are tuned by optimization algorithms and DC/DC boost converter respectively. The simulation results establish that the controller yields superior results through diverse climate circumstances compared to existing approaches. The simulation results demonstrate the effectiveness of the implemented ANN- PSO- SA fuzzy PID algorithm. In the future research, this work will be further extended with a detailed comparison of the meta-heuristic algorithms for optimization of Fuzzy-PID. Further this work will also incorporated hardware design.

\section{References}

1. Ahmed J, Salam Z. A Maximum Power Point Tracking (MPPT) for PV system using Cuckoo Search with partial shading capability. Applied Energy. 2014; 119: 118-130. https://doi.org/10.1016/j.apenergy.2013.12.062.

2. Sanjeevikumar P, Grandi G, Wheeler PW, Blaabjerg F, Loncarski J. A simple MPPT algorithm for novel PV power generation system by high output voltage DC-DC boost converter. In: Industrial Electronics. 2015; 214-220. https:// doi.org/10.1109/ISIE.2015.7281471.

3. Liu N, Chen Q, Liu J, Lu X, Li P, Lei J, Zhang J. A heuristic operation strategy for commercial building micro grids containing EVs and PV system. IEEE Transactions on Industrial Electronics. 2015; 62(4):2560-2570. https://doi. org/10.1109/TIE.2014.2364553.
4. Bendib B, Krim F, Belmili H, Almi MF, Boulouma S. Advanced Fuzzy MPPT Controller for a stand-alone PV system. Energy Procedia. 2014; 50: 383-392. https://doi. org/10.1016/j.egypro.2014.06.046.

5. Sundareswaran K, Vigneshkumar V, Sankar P, Simon SP, Nayak PSR, Palani S. Development of an improved P\&O algorithm assisted through a colony of foraging ants for MPPT in PV system. IEEE Transactions on Industrial Informatics. 2016; 12(1): 187-200. https://doi.org/10.1109/ TII.2015.2502428.

6. Montoya DG, Ramos-Paja CA, Giral R. Improved design of sliding-mode controllers based on the requirements of MPPT techniques. IEEE transactions on Power Electronics. 2016; 31(1): 235-247. https://doi.org/10.1109/ TPEL.2015.2397831.

7. Mohapatra A, Nayak B, Das P, Mohanty KB. A review on MPPT techniques of PV system under partial shading condition. Renewable and Sustainable Energy Reviews. 2017; 80: 854-867. https://doi.org/10.1016/j. rser.2017.05.083.

8. Mohanty P, Bhuvaneswari G, Balasubramanian R, Kaur Dhaliwal N. MATLAB based modeling to study the performance of different MPPT techniques used for solar PV system under various operating conditions. Renewable and Sustainable Energy Reviews. 2014; 38: 581-593. https:// doi.org/10.1016/j.rser.2014.06.001.

9. Dounis AI, Stavrinidis S, Kofinas P, Tseles D. Fuzzy-PID controller for MPPT of PV system optimized by Big BangBig Crunch algorithm. In: Fuzzy Systems (FUZZ-IEEE). IEEE International Conference. 2015; 1-8. https://doi. org/10.1109/FUZZ-IEEE.2015.7338060.

10. Harrag A, Messalti S. Variable step size modified P\&O MPPT algorithm using GA-based hybrid offline/online PID controller. Renewable and Sustainable Energy Reviews. 2015; 49: 1247-1260. https://doi.org/10.1016/j. rser.2015.05.003.

11. Kofinas P, Dounis AI, Papadakis G, Assimakopoulos MN. An Intelligent MPPT controller based on direct neural control for partially shaded PV system. Energy and Buildings. 2015; 90: 51-64. https://doi.org/10.1016/j. enbuild.2014.12.055.

12. Lal DK, Barisal AK, Tripathy M. Load frequency control of multi area interconnected microgrid power system using grasshopper optimization algorithm optimized fuzzy PID controller. In: Recent Advances on Engineering, Technology and Computational Sciences. 2018; 1-6. https://doi.org/10.1109/RAETCS.2018.8443847.

13. Mamizadeh A, Genc N, Rajabioun R. Optimal Tuning of PI Controller for Boost DC-DC Converters Based on Cuckoo Optimization Algorithm. In: 7th International Conference 
on Renewable Energy Research and Applications. 2018; 677-680. https://doi.org/10.1109/ICRERA.2018.8566883.

14. Sahu RK, Shaw B. Design of Solar System by Implementing ALO Optimized PID Based MPPT Controller. Trends in Renewable Energy. 2018; 4(3): 44-55. https://doi. org/10.17737/tre.2018.4.3.0049.

15. Yanlong W, Xuhong Y, Haoran L. The application of fuzzy-PID control in PV generation of DC-DC converter. International Conference on Intelligent Systems Research and Mechatronics Engineering ISRME. 2015; 1183-1187.

16. Liu L, Meng X, Liu C. A review of maximum power point tracking methods of PV power system at uniform and partial shading. Renewable and Sustainable Energy Reviews. 2016; 53: 1500-1507. https://doi.org/10.1016/j. rser.2015.09.065.

17. Sai Saranya DN, Polamraju and V. S. Sobhan. Adaptive Fuzzy Pid Controller Based Maximum Power Point Tracking For PV Fed DC Motor Drive. IJCTA. 2016; 9(29): 31-39.

18. Sabir MM, Ali T. Optimal PID controller design through swarm intelligence algorithms for sun tracking system. Applied Mathematics and Computation. 2016; 274: 690699. https://doi.org/10.1016/j.amc.2015.11.036.

19. Dounis AI, Kofinas P, Alafodimos C, Tseles D. Adaptive fuzzy gain scheduling PID controller for maximum power point tracking of photovoltaic system. Renewable energy. 2013; 60: 202-214. https://doi.org/10.1016/j. renene.2013.04.014.

20. Chaiyatham T, Ngamroo I. Improvement of power system transient stability by PV farm with fuzzy gain scheduling of PID controller. IEEE Systems Journal. 2017; 11(3): 16841691. https://doi.org/10.1109/JSYST.2014.2347393.

21. Guedes OM, Adilson de Castro J. Development of a Dynamic Model Based On the PID Control and Optimization Theories to Evaluate the Integrated
Performance of the Energy Generation and Storage System. International Journal of Innovative Research in Engineering \& Management. 2017; 4(4): 2350-0557. https://doi.org/10.21276/ijirem.2017.4.4.2.

22. Kalaam RN, Muyeen SM, Al-Durra A, Hasanien HM, Al-Wahedi K. Optimization of controller parameters for grid-tied photovoltaic system at faulty network using artificial neural network-based cuckoo search algorithm. IET Renewable Power Generation. 2017; 11(12): 15171526. https://doi.org/10.1049/iet-rpg.2017.0040.

23. Chen YT, Jhang YC, Liang RH. A fuzzy-logic based autoscaling variable step-size MPPT method for PV systems. Solar Energy. 2016; 126: 53-63. https://doi.org/10.1016/j. solener.2016.01.007.

24. Rawat S, Jha B, Panda MK. Operation and Control of a Hybrid Isolated Power System with Type-2 Fuzzy PID Controller. Iranian Journal of Science and Technology, Transactions of Electrical Engineering. 2018; 42(4): 403417. https://doi.org/10.1007/s40998-018-0070-8.

25. Farayola AM, Sun Y, Ali A. ANN-PSO Optimization of PV Systems under Different Weather Conditions. In: 7th International Conference on Renewable Energy Research and Applications. 2018; 1363-1368. https://doi. org/10.1109/ICRERA.2018.8566974

26. Sudibyo S, Murat MN, Aziz N. Simulated annealing-Particle Swarm Optimization (SA-PSO): particle distribution study and application in Neural Wiener-based NMPC. In: Control Conference (ASCC), 10th Asian. 2015; 1-6. https:// doi.org/10.1109/ASCC.2015.7244567.

27. Kottas T, Stimoniaris D, Tsiamitros D, Kikis V, Boutalis Y, Dialynas E. New operation scheme and control of Smart Grids using Fuzzy Cognitive Networks. In: Power Tech. IEEE Eindhoven. 2015; 1-5. https://doi.org/10.1109/ PTC.2015.7232563. 